\title{
Using Gold Nanoparticles as Passive Sampler for Indoor Monitoring of Gaseous Elemental Mercury
}

\author{
Elias B. Santos, ${ }^{*, a}$ Stacy Ferlin, ${ }^{b}$ Anne H. Fostier ${ }^{*, b}$ and Italo O. Mazali ${ }^{*, c}$ \\ ${ }^{a}$ Instituto de Ciência e Tecnologia, Universidade Federal de São Paulo (UNIFESP), \\ 12231-280 São José do Campos-SP, Brazil \\ ${ }^{b}$ Instituto de Química and ${ }^{c}$ Laboratório de Materiais Funcionais, Instituto de Química, \\ Universidade Estadual de Campinas (UNICAMP), P.O. Box 6154, 13083-970 Campinas-SP, Brazil
}

This study reports a functional passive sampler for monitoring gaseous elemental mercury (GEM). The material consists of gold nanoparticles (AuNP) deposited forming a film on thiolmodified glass slides. AuNP colloid was synthesized using sodium citrate, resulting in a size of $24.2 \pm 0.8 \mathrm{~nm}$, as determined by transmission electron microscopy analysis. For the indoor test, AuNP films were placed into Petri plates. One part of the lot was kept exposed to the laboratory's atmosphere and the other part was stored in closed plate (control). The films were removed from both plates along a month and analyzed using a direct mercury analyzer. A linear relationship between $\mathrm{Hg}$ retention and exposure time was obtained until the $23^{\text {rd }}$ day, which allowed to calculate a GEM retention rate of $2.2 \mathrm{ng} \mathrm{g}^{-1} \mathrm{day}^{-1}$; the maximum retention capacity was around $50 \mathrm{ng} \mathrm{g}^{-1}$. This study provides an efficient method for indoor monitoring of GEM using AuNP films as passive sampler.

Keywords: gold nanoparticles, passive sampler, mercury, indoor monitoring

\section{Introduction}

Mercury $(\mathrm{Hg})$ is emitted to the atmosphere by both natural process (e.g. volcanoes, crustal degassing, reemission from aquatic and terrestrial surfaces), and human activities (e.g. fossil fuel-fired power plants, gold mining, cement production, chlor-alkali plants). ${ }^{1}$ Atmospheric mercury forms are currently operationally defined as gaseous elemental $\mathrm{Hg}(\mathrm{GEM})$, gaseous oxidized $\mathrm{Hg}(\mathrm{GOM})$, and particulate-bound $\mathrm{Hg}(\mathrm{PBM}) .{ }^{2} \mathrm{GEM}$ is a stable monatomic gas with similar properties to noble gases, which accounts for more than $90 \%$ of the atmospheric mercury. ${ }^{2,3}$ Its residence time in the atmosphere is of the order of one year or more, allowing for the global distribution and cycling of mercury. ${ }^{3}$ Background concentration of airborne mercury is presently considered to be in the range of 1.1 to $1.7 \mathrm{ng} \mathrm{m}^{-3} .4$ Once in the atmosphere, $\mathrm{Hg}$ can remain airborne or be deposited in aquatic and terrestrial surfaces by wet and dry deposition. In aquatic environment, inorganic mercury can be converted to methylmercury, which is the most toxic $\mathrm{Hg}$ compound. Further, methylmercury bio accumulates in

*e-mail: eliasbarsan@gmail.com; fostier@iqm.unicamp.br; mazali@iqm.unicamp.br aquatic food chain and adversely affects human health on a global scale through fish consumption. ${ }^{5,6}$ GEM is also a hazardous material, and it has been reported that high level exposure can harm the human brain, heart, kidneys, lungs and immune system..$^{7-9}$ Guidelines for exposure to mercury include: $1 \mu \mathrm{g} \mathrm{m}^{-3}$ for air (annual average) and $0.2 \mu \mathrm{g} \mathrm{m}^{-3}$ for long-term exposure to elemental mercury vapor (FAO/WHO, 2007). ${ }^{10}$

Monitoring concentrations of atmospheric mercury can therefore provide important information for a global assessment, and for global and regional model evaluation and extrapolation as well. ${ }^{4}$ Such monitoring is also needed in order to evaluate workers' exposure to GEM released in some activities (chlor-alkali plants, mercury recycling plants, artisanal and small gold-mines, etc.).

Current procedures that allow quantitation of atmospheric GEM generally include a collecting phase on some suitable material (mainly based on direct amalgamation process between $\mathrm{Au}$ and $\mathrm{Hg}$ ) and a step of $\mathrm{Hg}$ detection mainly based on cold vapor atomic absorption spectrometry (CV-AAS) or atomic fluorescence spectrometry (CV-AFS) ${ }^{11-13}$ Although fully automated systems for atmospheric mercury sampling and measurement are available, they usually imply large financial investment and high continuous operating costs for 
gas and energy supply and also require trained technical staff on location or relatively nearby. In contrast, passive samplers are able to trap gases (e.g. GEM) at a controlled rate by physical processes such as diffusion, without active sampling on the trap. Mercury is then desorbed and quantify in the same way than for active samplers. These sampling devices are simple to deploy, require no power supply or special gases, which allows them to be placed in relatively remote areas. They normally stay in the sampling area for days or weeks and can be analyzed at a central laboratory., ${ }^{4}$ In the last few years, researches have therefore been conducted for the development of passive samplers for indoor or ambient GEM and other mercury species, as recently reviewed by Huang et al. ${ }^{14}$ The direct amalgamation between $\mathrm{Au}$ and $\mathrm{Hg}$ is generally the basic process used in mercury samplers, and a large variety of materials based on nanotechnology have already been applied for this purpose. ${ }^{15-18}$ However, the state of art in those nanomaterials-based passive samplers is still in early stage. ${ }^{14,19}$

This paper describes the preparation and performance of a GEM passive sampler based on gold nanoparticles for indoor monitoring. The material consists of gold nanoparticles deposited as a film on SH-modified glass slides (ca. $1.0 \mathrm{~cm}^{2}$ ), which was tested in a laboratory's atmosphere for one month.

\section{Experimental}

\section{Chemicals}

Chloroauric acid (ACS grade), sodium citrate dihydrate, 3-mercaptopropyl-trimetoxisilane (MPTMS), ethylic alcohol (ACS grade), hydrogen peroxide, hydrochloric and sulfuric acid were purchased from Sigma-Aldrich. All chemicals were used as received.

\section{Gold nanoparticles synthesis}

Before synthesis, all glassware was cleaned using piranha solution (25\% hydrogen peroxide in sulfuric acid $\mathrm{v} / \mathrm{v}$ ), rinsed with deionized water, and dried at $100{ }^{\circ} \mathrm{C}$ to remove residual water. Gold nanoparticles (AuNP) were prepared according to the Lee and Meisel method with some few changes..$^{20}$ Briefly, $\mathrm{HAuCl}_{4}$ aqueous solution $\left(1.0 \mathrm{~L}, 0.5 \times 10^{-3} \mathrm{~mol} \mathrm{~L}^{-1}\right)$ was heated to boiling point under vigorous stirring. Then, sodium citrate $(10 \mathrm{~mL}, 2.5 \% \mathrm{~m} / \mathrm{v})$ was rapidly added into the solution. The reaction mixture was kept under heating and stirring during $15 \mathrm{~min}$, which resulted in the solution changing to a wine-red color. After that, heating was ceased and stirring was kept for another 15 min to complete the reaction.

\section{AuNP films preparation}

AuNP films were prepared following a procedure reported elsewhere replacing the silane compound by MPTMS. ${ }^{21}$ Microscope regular glass slides were cut in ca. $1.0 \times 1.0 \mathrm{~cm}$ small slides, cleaned using piranha solution $\left(70{ }^{\circ} \mathrm{C}\right.$ for $\left.1 \mathrm{~h}\right)$ to remove any organic material. Subsequently, the slides were rinsed with deionized water and dried using $\mathrm{N}_{2}$ flow. After that, they were soaked in a $10 \%$ solution of MPTMS in ethanol overnight. Afterward, they were removed from the MPTMS solution and rinsed copiously with ethanol, followed by deionized water, and then dried under a gentle stream of $\mathrm{N}_{2}$.

To add a AuNP layer, the cleaned glass slides were immersed in as-prepared gold nanoparticles colloidal solution for $5 \mathrm{~h}$. After this period, the slides were removed and rinsed with copious amounts of deionized water, and then dried under a gentle stream of $\mathrm{N}_{2}$.

Characterization and determination of concentration of gold nanoparticles

UV-Visible absorption spectra of AuNP colloidal solution and of AuNP films were collected on an Agilent Cary probe $50 \mathrm{UV}-\mathrm{Vis}$ spectrometer. For transmission electron microscopy (TEM) analysis, samples were prepared by drop-drying AuNP colloidal solution on a carbon-coated copper grid. TEM images were obtained using a JEOL JEM-2100 microscope $(200 \mathrm{kV}, 0.25 \mathrm{~nm}$ point resolution). For scanning electron microscopy (SEM) analysis, AuNP substrates were covered with a thin carbon film. SEM images were obtained using a field emission gun microscope, model FEI Inspect 50, with acceleration voltage of $15 \mathrm{kV}$. Also, an energy-dispersive X-ray spectroscopy (EDS) elemental analysis was carried out.

The as-synthesized AuNP colloidal solution was centrifuged at $10000 \times \mathrm{g}$ in a falcon tube for $60 \mathrm{~min}$, obtaining the supernatant solution plus the AuNP at the bottom of the tube. This procedure was performed in triplicate. The centrifugation time was determined by evaluating the UV-Vis spectrum from the AuNP supernatant at different times until obtaining a base line signal, which indicated that the major content of gold nanoparticles were settled. A $5 \mathrm{~mL}$ volume of each AuNP part mixed with $2 \mathrm{~mL}$ of a concentrated sub-boiled $\mathrm{HNO}_{3}$ plus $0.5 \mathrm{~mL}$ of $30 \%(\mathrm{~m} / \mathrm{v}) \mathrm{H}_{2} \mathrm{O}_{2}$ was subjected to microwave-assisted decomposition using the following program: $5 \mathrm{~min}$ at $400 \mathrm{~W}, 8 \mathrm{~min}$ at $790 \mathrm{~W}, 4 \mathrm{~min}$ at $320 \mathrm{~W}, 3 \mathrm{~min}$ at $0 \mathrm{~W}$. After that, the decomposed samples were diluted 4000 times and analyzed by inductively coupled plasma mass spectrometry (ICP-MS, PerkinElmer, Norwalk, CT, USA). 
Gaseous elemental mercury monitoring and analytical method for mercury quantitation

The indoor test was conducted at University of Campinas, in a Chemistry laboratory, where there are no mercury emission sources and contamination. AuNP films were divided in two groups and placed into two batches of Petri plates, one kept exposed to the laboratory atmosphere and the other stored in closed plates sealed with Teflon tape (control). Three samples of both batches were removed along one month and they were analyzed by using a Direct Mercury Analyzer ${ }^{\circledR}$ (DMA-80 TRICELL, Milestone, Italy). The equipment associates thermal decomposition, amalgamation and atomic absorption spectrometry and the method is recognized by the U.S. EPA for determination of total $\mathrm{Hg}$ in solid and liquid samples. ${ }^{11,22,23}$

All samples were dried with a $\mathrm{N}_{2}$ flow before DMA analysis to prevent dust contamination of the environment. This equipment contains an automatic sampler, a quartz furnace, a cobalt-manganese oxide catalyst, a gold-coated sand amalgamator and an atomic absorption detection cell with three different path lengths. The different steps of the analysis are controlled by software.

For analysis, each sample (colloidal solution or glass slide) was placed in a nickel boat of approximately $360 \mathrm{~mm}$ (length), $110 \mathrm{~mm}$ (width) and $110 \mathrm{~mm}$ (height) which was automatically inserted into the furnace under an oxygen flow, also serving as carrier gas. In this device, possible interfering species are removed onto the catalyst; the $\mathrm{Hg}^{0}$ is selectively retained onto the amalgamator and then thermally desorbed and carried out to the detection cell; detection is performed at $253.7 \mathrm{~nm}$.

The calibration curve $(0.1$ to $20 \mathrm{ng} \mathrm{Hg})$ was obtained by triple analyses of 10 to $200 \mu \mathrm{L}$ aliquots of $\mathrm{Hg}$ standard solutions (10 or $100.0 \mu \mathrm{g} \mathrm{L}{ }^{-1}$ depending on the desired final amount of $\mathrm{Hg}$ ) prepared from a stock $\mathrm{Hg}$ standard solution $\left(1.000 \pm 0.003 \mathrm{mg} \mathrm{mL}^{-1}\right)\left(\right.$ Tec-Lab $^{\circledR}$ Hexis, Jundiaí, Brazil $)$ diluted in a $10 \%(\mathrm{v} / \mathrm{v}) \mathrm{HNO}_{3}$ solution. The method was in-lab validated by the evaluation of the following parameters: linear range, linearity, matrix effect, precision, accuracy and limit of detection (LOD) and of quantification (LOQ).

Different volumes $(50,100$, and $200 \mu \mathrm{L})$ of the AuNP colloid solution were analyzed in order to verify if the colloid was not $\mathrm{Hg}$ contaminated. For the evaluation of matrix effects, calibration curve was constructed using $150 \mu \mathrm{L}$ aliquots of AuNP colloidal solution fortified with 10 to $50 \mu \mathrm{L}$ of 10.0 or $100.0 \mu \mathrm{g} \mathrm{L}^{-1} \mathrm{Hg}^{\mathrm{II}}$ standard solution. The slope of this curve was compared with the slope of the curve constructed in acidic solution. The accuracy was checked by recovery test when 0.5 and $5.0 \mathrm{ng}$ of $\mathrm{Hg}^{\mathrm{II}}$ was added to 50, 100, 150 and $200 \mu \mathrm{L}$ of AuNP colloidal solution. Each recovery test was performed in triplicate in order to evaluate the precision. The LOD and LOQ were determined as 3 and 10 times the standard deviation of the residuals from the linear regression, respectively, divided by the angular coefficient value of the linear equation.

\section{Results and Discussion}

The UV-Vis absorption spectrum of the AuNP colloid is shown in Figure 1a, where it can be observed that the surface plasmon resonance (SPR) band with maximum absorbance is at $526 \mathrm{~nm}$. This SPR band is an UV-Vis spectral signature of formation of spherical gold nanoparticles, as previously reported elsewhere. ${ }^{24-26}$

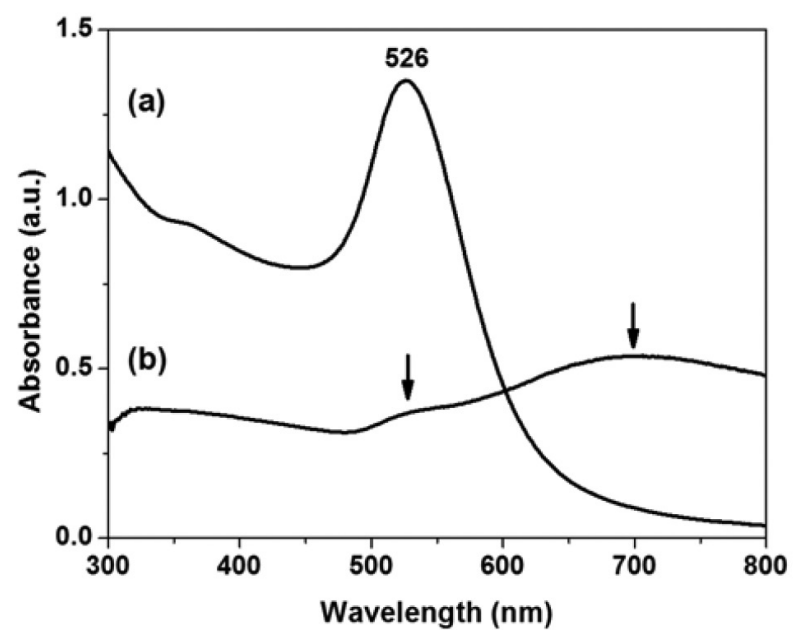

Figure 1. UV-Vis absorption spectra of the AuNP colloid (a) and of the AuNP film (b).

As observed in Figure 1b, an SPR band can be identified around $526 \mathrm{~nm}$, however, with low intensity in the UV-Vis spectrum of the AuNP substrate. In the same UV-Vis spectrum a broad band around $700 \mathrm{~nm}$ is also observed, and it can be associated with the formation of AuNP junctions and aggregates, ${ }^{27,28}$ as shown in the SEM images (Figure 2) with different magnifications. The AuNP are uniformly distributed over all the entire surface of the glass support. This feature can be an advantage during the mercury monitoring, which can contribute to an uniform adsorption of $\mathrm{Hg}^{0}$, and subsequently $\mathrm{Au}-\mathrm{Hg}$ amalgamation on the AuNP substrate surface.

The representative TEM image (Figure 3a) shows the spherical-like shape morphology of the AuNP with size distribution centered in $24.2 \mathrm{~nm}$, fitted with a log-normal distribution (Figure 3b). Also, the gold nanoparticles are highly crystalline as shown in the high magnification TEM image (Figure 3c). The hexagonal FFT pattern clearly shows the electron diffraction pattern for gold nanoprism 

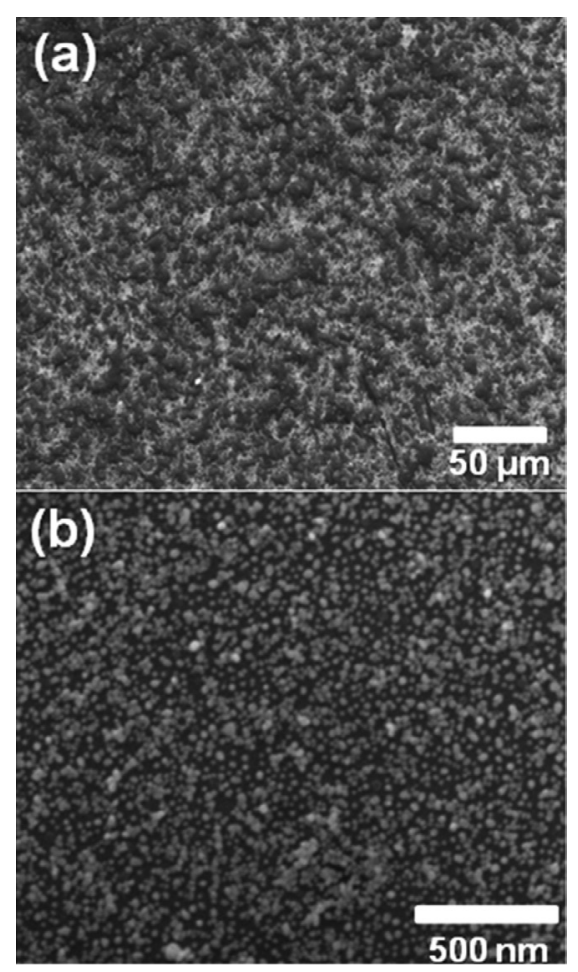

Figure 2. SEM images of the AuNP film in low magnification (a) and high magnification (b).

structure (Figure 3d). The d-spacing of the corresponding FFT image were calculated to be 2.4, 2.3 and $2.2 \AA$. They were indexed according to the diffraction planes of fcc gold, as shown in Figure 3d, corresponding to [111] zone axis. ${ }^{28}$
The performance of the AuNP film as GEM passive sampler is directly dependent on the quality of the gold nanoparticles colloid. Thus, the AuNP colloid was analyzed by UV-Vis on different days ( 1 to 28 days after its preparation) in order to assess its stability as function of time. The UV-Vis spectra during the 28 days are shown in Figure 4. All UV-Vis spectra are similar to each other, and no significant changes can be observed comparing their spectral profiles. This result shows that gold nanoparticles colloid remained stable at least during the period of the AuNP films application. Previous works reported that colloidal solutions of gold nanoparticles synthesized using sodium citrate are stable for at least one year. ${ }^{26,29}$

The concentration of gold nanoparticles in the AuNP colloidal solution was determined from the ICP-MS data and it is shown in Table 1. This concentration was estimated from the total amount of gold found in the bottom of the tube after the centrifugation procedure. However, the total amount of gold determined in the supernatant part $\left(17 \pm 1 \mu \mathrm{g} \mathrm{L}{ }^{-1}\right)$ is due to presence of $\mathrm{Au}^{3+}$ ions, which remains in the solution. This result indicates that $82 \%$ of the total $\mathrm{Au}^{3+}$ ions are converted to $\mathrm{Au}^{0}$, which are forming the gold nanoparticles.

Mercury amalgams are alloys formed by the interaction of zero valent mercury with other metals, especially gold and silver, due to its high chemical affinity for these elements. This specificity of amalgam formation between gold and mercury is explored in the present system using AuNP films as passive GEM sampler.
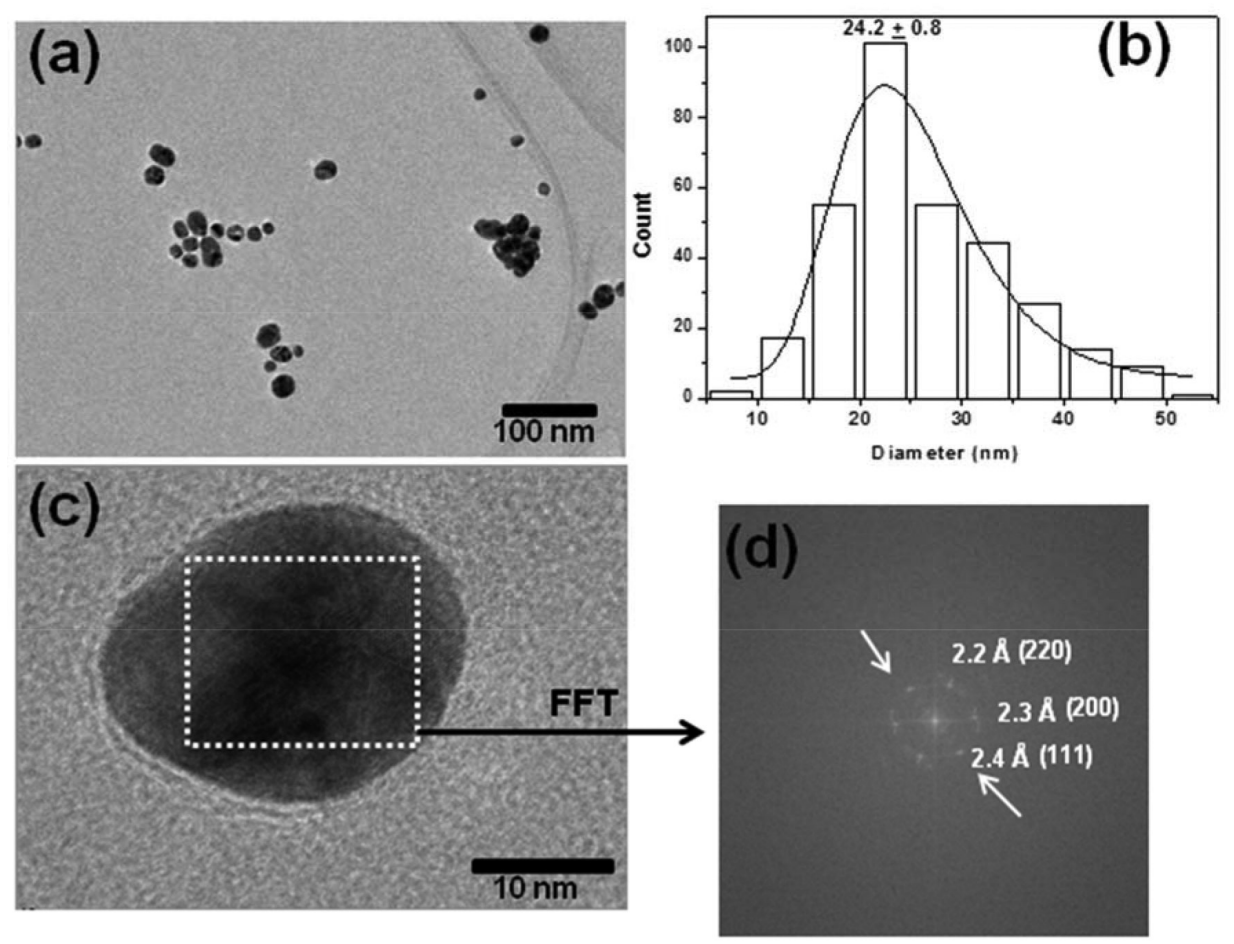

Figure 3. TEM image (a) and histogram of size distribution (b) of the AuNP. TEM image of a gold nanoprism (c) and its corresponding FFT image (d). 


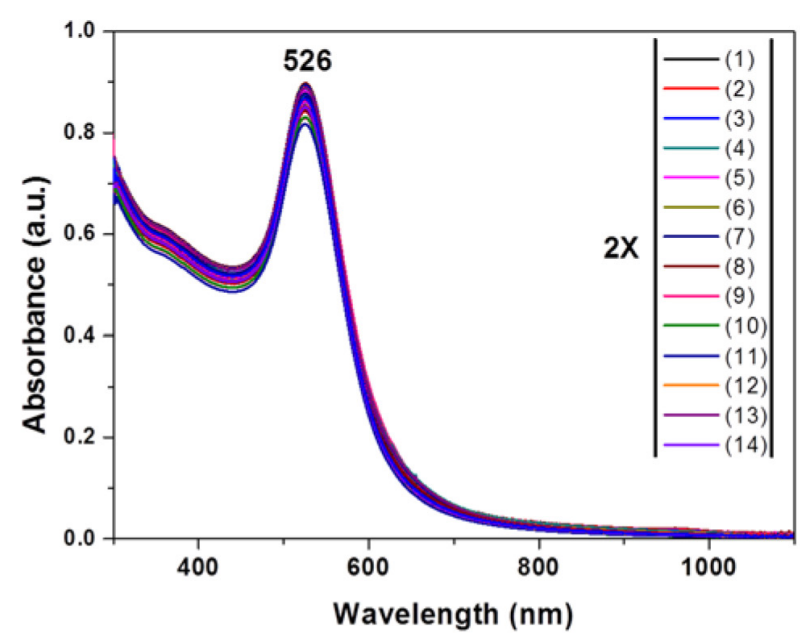

Figure 4. UV-Vis absorption spectra of the AuNP colloid for 28 days. The pattern of colors is repeated two times for 14 spectra, and it is represented by $2 \times$ with reference to 28 spectra.

Table 1. Quantification by ICP-MS of AuNP in the colloidal solution and its parts, centrifuged AuNP and supernatant

\begin{tabular}{lc}
\hline Parts of AuNP colloidal solution & Concentration / $\left(\mu \mathrm{g} \mathrm{L}^{-1}\right)$ \\
\hline AuNP colloid & $98 \pm 4$ \\
Centrifuged AuNP & $80 \pm 2$ \\
Supernatant & $17 \pm 1$ \\
\hline
\end{tabular}

The analysis of different volumes $(50,100$, and $200 \mu \mathrm{L})$ of the AuNP colloid solution used for films preparation showed that the colloid was not $\mathrm{Hg}$ contaminated. No significant matrix effect was observed when comparing (Student's $t$-test, 95\% confidence level) the slopes of the calibration curves constructed in acidic solution and in AuNP colloid solution. The calibration curve was therefore constructed in acidic solution and the linear range was 0.1-5.0 ng Hg with correlations (r) above 0.99. The LOD and LOQ were 0.15 and $0.49 \mathrm{ng} \mathrm{Hg}$, respectively. The recovery ranged between 89.3 and $94.8 \%$ and between 99.0 and $105.4 \%$ when different volumes of AuNP colloid solution were fortified with 0.5 and $5.0 \mathrm{ng} \mathrm{Hg}$, respectively. For these tests, the precision expressed as the relative standard deviation $(\mathrm{n}=3)$ was $<12.6 \%$ and $<1.4 \%$ for fortification with 0.5 and $5.0 \mathrm{ng} \mathrm{Hg}$, respectively.

One of the principles of passive sampler is that the sampler allows quantifying the amount of a target compound (m) that is trapped on the sorbent from the atmosphere over a given period of time. Ideally, $\mathrm{m}$ is a linear function of the deployment time and the length of the linear retention period determines the maximum length of deployment and allows to calculate the retention capacity. ${ }^{30}$

In order to check these parameters, the amount of GEM determined by DMA was divided by the mass of the correspondent AuNP film and the values are shown in Figure 5 as function of the exposure time. As it can be observed, a linear relationship between the mercury retention and the exposure time was obtained until the $23^{\text {rd }}$ day $\left(R^{2}=0.95\right)$. The distribution profile of the data suggests a trend of sampler saturation after this time. The linear regression equation calculated from the data between 0 and 23 days gives a retention rate of $2.2 \mathrm{ng} \mathrm{g}^{-1}$ day $^{-1}$ and a retention capacity around $50 \mathrm{ng} \mathrm{g}^{-1}$. The analysis of the AuNP films used as control revealed the presence of mercury $(6.2 \pm 1.5 \mathrm{ng})$ only on the last three stored samples (all analyzed on the $30^{\text {th }}$ day). This result is very interesting, showing that until the $23^{\text {rd }}$ day no mercury was detected in the AuNP stored samples. This also suggests that the performance of the GEM passive sensor was constant, reproducible and stable during that period.

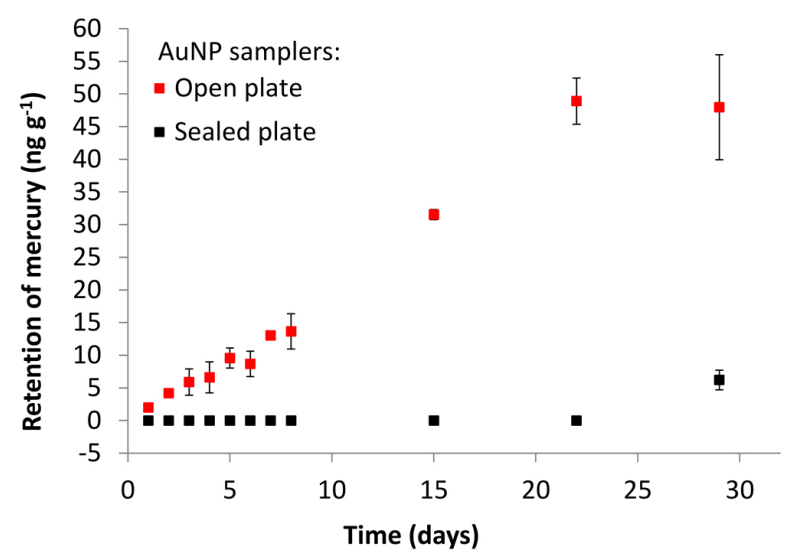

Figure 5. Retention of GEM for stored and exposed AuNP films in function of the time (the error bar corresponds to standard deviation for triplicate analyses).

After mercury quantitation by DMA, the AuNP films were analyzed again by SEM, and a representative image is shown in Figure 6a. It can be observed that there is a significant amount of gold nanoparticles in the sample, even after DMA analysis. Besides, the EDS spectrum in Figure $6 \mathrm{~b}$ shows peaks corresponding to gold, and there is no evidence of presence of mercury. This result indicates that heating the samples during the DMA analysis is enough to decompose the $\mathrm{Au}-\mathrm{Hg}$ amalgam, releasing all mercury to be quantified. Also, this result supports the DMA analysis, indicating that all captured GEM by the AuNP films was quantified. Other elements such as $\mathrm{Ca}, \mathrm{Si}$ and $\mathrm{Na}$ observed in the EDS spectrum are attributed to composition of the glass support (Figure 6b).

Comparing the SEM images of Figures 2 and 6, it is evident that after the DMA analysis the organization of AuNP on glass support is different. Also, it can be observed the formation of largest gold particles induced 

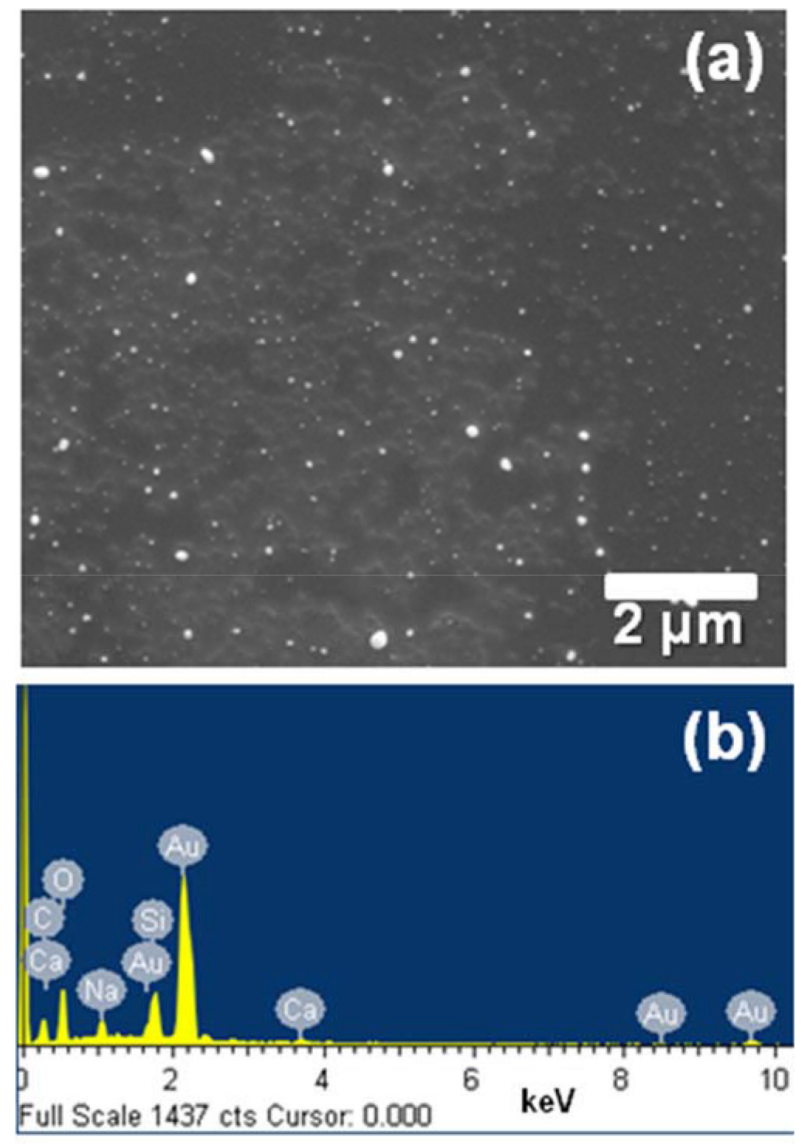

Figure 6. SEM image (a) and EDS analysis (b) of a representative AuNP film after mercury quantitation by DMA.

by the heating during the DMA analysis. Notwithstanding the difference observed for the AuNP films surface, the presence of a significant amount of gold on the slide after DMA analysis and the absence of mercury suggest that AuNP sampler can be reused for GEM monitoring.

\section{Conclusions}

Gold nanoparticles were synthesized using sodium citrate as reducing and stabilizer agent with an yield of ca. $82 \%$, which was estimated by ICP-MS analysis. AuNP colloid was used to prepare gold nanoparticles films that were employed as passive sampler for gaseous elemental mercury. Passive GEM sampling at research laboratory showed that the AuNP passive sampler is suitable for monitoring the presence of mercury in such ambient for at least one month. The linear correlation between the GEM retention and the exposure time of AuNP films to the ambient atmosphere allowed estimating the retention rate, which was $2.2 \mathrm{ng} \mathrm{g}^{-1}$ day $^{-1}$. The AuNP films proved to be stable during the monitoring time, it is a low cost material and sensitive to the presence of GEM. Moreover, although no reusable test of the AuNP films has been carried out, the high concentration of gold nanoparticles on the material after DMA analysis suggests that the AuNP sampler can be utilized again for the same application. This preliminary study opens the possibility of more investigations to improve the performance of AuNP films as passive sampler for indoor or even outdoor GEM monitoring.

\section{Acknowledgments}

E. B. S. thanks FAPESP for a post-doc fellowship (2012/19485-1) and S. F. thanks CNPq for undergraduate fellowship. The authors would like to thank the FAPESP, CAPES and $\mathrm{CNPq}$ for financial support. Contributions from Brazilian Nanotechnology National Laboratory (LNNano, Campinas-SP, Brazil) for SEM and TEM analysis are also appreciated.

\section{References}

1. Pirrone, N.; Cinnirella, S.; Feng, X.; Finkelman, R. B.; Friedli, H. R.; Leaner, J.; Mason, R.; Mukherjee, A. B.; Stracher, G. B.; Streets, D. G.; Telmer, K.; Atmos. Chem. Phys. 2010, 10, 5951.

2. Pacyna, E. G.; Pacyna, J. M.; Steenhuisen, F.; Wilson, S.; Atmos. Environ. 2006, 40, 4048.

3. Selin, N. E.; Annu. Rev. Environ. Resour. 2009, 34, 43.

4. Pirrone, N.; Aas, W.; Cinnirella, S.; Ebinghaus, R.; Hedgecock, I. M.; Pacyna, F.; Atmos. Environ. 2013, 80, 599.

5. Driscoll, C. T.; Mason, R. P.; Chan, H. M.; Jacob, D. J.; Pirrone, N.; Environ. Sci. Technol. 2013, 47, 4967.

6. Karagas, M. R.; Choi, A. L.; Oken, E.; Horvat, M.; Schoeny, R.; Kamai, E.; Cowell, W.; Grandjean, P.; Korrick, S.; Environ. Health Perspect. 2012, 120, 799.

7. Ballatori, N.; Environ. Health Perspect. 2002, 110, 689.

8. Diez, S.; Rev. Environ. Contam. Toxicol. 2009, 198, 111.

9. Farina, M.; Aschner, M.; Rocha, J. B. T.; Toxicol. Appl. Pharmacol. 2011, 250, 405.

10. Whqlibdoc.who.int/trs/WHO_TRS_940_eng.pdf, accessed on August 30, 2016.

11. Ferlin, S.; Fostier, A. H.; Mendez-Perez, J. J.; Anal. Methods 2014, 6, 4537.

12. Pandey, S. K.; Kim, K. H.; Brown, R. J. C.; Trends Anal. Chem. 2011, 30, 899.

13. Kim, H. N.; Ren, W. X.; Kim, J. S.; Yoon, J.; Chem. Soc. Rev. 2012, 41, 3210.

14. Huang, J.; Lyman, S. N.; Hartman, J. S.; Gustin, M. S.; Environ. Sci.: Processes Impacts 2014, 16, 374.

15. James, J. Z.; Lucas, D.; Koshland, C. P.; Environ. Sci. Technol. 2012, 46, 9557.

16. Sedghi, R.; Heidari, B.; Behbahani, M.; J. Hazard. Mater. 2015 , 285, 109. 
17. Zhang, Y.; Zeng, G.; Tang, L.; Li, Y.; Chen, Z.; Huang, G.; RSC Adv. 2014, 4, 18485.

18. Kang, T.; Yoo, S. M.; Kang, M.; Lee, H.; Kim, H.; Lee, S. Y.; Kim, B.; Lab Chip 2012, 12, 3077.

19. Botasini, S.; Heijo, G.; Mendez, E.; Anal. Chim. Acta 2013, 800, 1 .

20. Lee, P. C.; Meisel, D.; J. Phys. Chem. 1982, 86, 3391.

21. Santos, E. B.; Sigoli, F. A.; Mazali, I. O.; Vib. Spectrosc. 2013, 68, 246.

22. Melendez-Perez, J. J.; Fostier, A. H.; J. Braz. Chem. Soc. 2013, $24,1880$.

23. United States Environmental Protection Agency (US EPA); Method 7473, Mercury in Solids and Solutions by Thermal Decomposition, Amalgamation, and Atomic Absorption Spectrophotometry; February, 2007.

24. Santos, E. B.; Sigoli, F. A.; Mazali, I. O.; J. Braz. Chem. Soc. 2015, 26, 970 .
25. Li, C.; Li, D.; Wan, G.; Xu, J.; Hou, W.; Nanoscale Res. Lett. 2011, 6, 440.

26. Ghosh, S. K.; Pal, T.; Chem. Rev. 2007, 107, 4797.

27. Klinkova, A.; Choueiri, R. M.; Kumacheva, E.; Chem. Soc. Rev. 2014, 43, 3976.

28. Shah, A. B.; Sivapalan, S. T.; DeVetter, B. M.; Yang, T. K.; Wen, J.; Bhargava, R.; Murphy, C. J.; Zuo, J.; Nano Lett. 2013, 13, 1840 .

29. Volkert, A. A.; Subramaniam, V.; Haes, A. J.; Chem. Commun. 2011, 47, 478.

30. McLagan, D. S.; Mazur, M. E. E.; Mitchell, C. P. J.; Wania, F.; Atmos. Chem. Phys. 2016, 16, 3061.

Submitted: August 30, 2016 Published online: November 3, 2016 